\title{
A Facile and Versatile Approach for the Synthesis of Degradable Polymers via Controlled Ring-Opening Metathesis Copolymerization
}

\section{John Feist}

Stanford University https://orcid.org/0000-0003-4032-1418

Daniel Lee

Stanford University https://orcid.org/0000-0003-4986-6027

Yan Xia ( $\nabla$ yanx@stanford.edu )

Stanford University https://orcid.org/0000-0002-5298-748X

\section{Keywords:}

Posted Date: March 23rd, 2021

DOI: https://doi.org/10.21203/rs.3.rs-281657/v1

License: (c) (i) This work is licensed under a Creative Commons Attribution 4.0 International License.

Read Full License

Version of Record: A version of this preprint was published at Nature Chemistry on November 18th, 2021. See the published version at https://doi.org/10.1038/s41557-021-00810-2. 


\section{Abstract}

The authors have requested that this preprint be removed from Research Square. 